\title{
Interventional benefit of Pilates using Oov and mat on middle-aged women with lower urinary tract symptoms: emphasis on abdominal muscle thickness and muscular function
}

\author{
Haelim Lee ${ }^{1, \dagger}$, Gyumin Kang ${ }^{2, \dagger}$, Hyunghoon Moon ${ }^{1}$, Junmin Lee ${ }^{3}$, Myungsung Kang ${ }^{4}$, Myung-Ki Kim ${ }^{5, *}$ \\ 'Department of Sports Medicine, College of Health Science, CHA University, Pocheon, Korea \\ ${ }^{2}$ School of Bio-Medical Science, Korea University, Sejong, Korea \\ ${ }^{3}$ Department of Physical and Occupational Therapy, Korea National Rehabilitation Center, Seoul, Korea \\ ${ }^{4} \mathrm{GC}$ Healthcare Corporation, Seoul, Korea \\ ${ }^{5}$ School of Global Sport Studies, Korea University, Sejong, Korea
}

Lower urinary tract symptoms (LUTS) have been considered as clinically prevalent symptom in women, and can be ameliorated by the change of abdominal muscles and pelvic floor muscle (PFM). This study investigated the efficacy of Pilates program using Oov and mat on the change of abdominal muscle thickness, PFM function, and LUTS clinical score. 53 women experiencing LUTS were randomly assigned to Oov Pilates exercise group (OPEG) $(n=20)$, mat Pilates exercise group (MPEG) $(n=$ $16)$, and symptomatic control group (SCG) $(n=17)$, respectively, and two groups using 0 ov and mat participated in 8-week Pilates program. Thickness of abdominal muscle, functional movement of PFM, and LUTS clinical score were measured from all groups. Thickness of rectus abdominis, internal oblique abdominis, transversus abdominis was significantly improved in OPEG $(P<0.05)$, however, MPEG showed a significant change only in transversus abdominis $(P<0.05)$. In all abdominal muscles, OPEG had a significantly improved abdominal muscle thickness compared to SCG $(P<0.05)$. Functional movement of PFM in OPEG was significantly decreased $(P<0.005)$, but not in MPEG and SCG. In LUTS clinical score, OPEG and MPEG showed a significantly abated symptoms in degree of voiding-related symptoms and discomfort $(P<0.005)$, but not in SCG. Our study highlighted that Pilates using Oov can be an effective intervention to ameliorate the quantitative quality of abdominal muscle thickness and PFM, which ultimately provides the satisfied self-clinical index in degree of voiding-related symptoms and discomfort.

Keywords: Pilates, Core exercise, Core muscle, Genitourinary disorder, Urinary incontinence, Micturition

\section{INTRODUCTION}

Lower urinary tract symptoms (LUTS) have been known to have a significant impact on the majority of adults over the age of 40 in women; the International Continence Society has reported that the incidence rate of LUTS in women is approximately $66.0 \%$ (Yoo et al., 2018). Urinary symptoms encompass a wide range of symptoms the clinical consequences of which affect the physiological control and quality of voiding in the urinary tract (Kim et al., 2018), and may occur during storage, voiding, and postmicturi-

*Corresponding author: Myung-Ki Kim (D) https://orcid.org/0000-0002-5821-9203 School of Global Sport Studies, Korea University, 2511 Sejong-ro, Jochiwon-eup, Sejong 30019, Korea

Email:kmk1905@korea.ac.kr

${ }^{\dagger}$ These authors contributed equally to this study as co-first authors.

Received: April 15, 2021 / Accepted: May 2, 2021

tion (Abrams et al., 2003). It was reported that aging in women gives rise to LUTS, which also impairs the urological function of the detrusor muscle, bladder volume, and urination ability (Davila and Guerette, 2004); consequently, LUTS associated with the aging was recognized to negatively impact on the quality of daily life such social and emotional wellness, work productivity, and sexual health (Coyne et al., 2008).

Pelvic floor muscle (PFM) is a multi-layered muscle complex that forms the base of the abdominal pelvic cavity that contributes to controlling the posture, abdominal pressure, and excretion

This is an Open Access article distributed under the terms of the Creative Commons Attribution Non-Commercial License (https://creativecommons.org/licenses/by-nc/4.0/) which permits unrestricted non-commercial use, distribution, and reproduction in any medium, provided the original work is properly cited. 
(Sapsford et al., 2008). Additionally, study showed that abdominal muscles such as the rectus abdominis, external oblique abdominis, internal oblique abdominis, and transversus abdominis helps to stabilize the trunk of the body (Hodges and Gandevia, 2000). In this sense, weakness and instability of the pelvic floor and abdominal muscles may cause precarious postural continuance of which anatomical structure may hinder the action of the pelvic structure.

It is reported that Pilates plays a pivotal role in enhancing the "Power-house" of the body such as the back, abdomen, and PFM (Fayh et al., 2018). Using repeated kinesiological movements and specialized breathing techniques, Pilates can facilitate not only the mobilization ability of the abdominal deep muscles but also the stability of the pelvis (Kim and Lee, 2017). More importantly, Pilates has been considered as a prophylactic approach for managing urinary incontinence, which can be achieved by strengthening the transversus abdominis and PFM (Bø and Herbert, 2013). In Pilates program settings, Oov known as the ergonomic-shape durable apparatus is designed to encourage the natural movement of the spine curvature; given that Pilates program using Oov showed a facilitated functional movement of PFM in women experiencing the urinary incontinence (Kang et al., 2021), the application of Oov can be a potential clinical approach to manage the LUTS. Considering the efficacy of Pilates program using the interventional apparatus such as Oov and mat has not been fully understood, the aim of our investigation was to examine the efficacy of Oov and mat Pilates on abdominal muscles thickness, functional movement of PFM, and LUTS self-clinical index.

\section{MATERIALS AND METHODS}

\section{Experimental participants}

A total of 53 women aged between 40 and 55 years were diagnosed with LUTS and randomly divided into three groups: Oov Pilates exercise group (OPEG) $(n=20)$, mat Pilates exercise group

Table 1. Anthropometrical assessment of subject

\begin{tabular}{lcccc}
\hline Group & Age $(\mathrm{yr})$ & Height $(\mathrm{cm})$ & Weight $(\mathrm{kg})$ & $\mathrm{BMl}\left(\mathrm{kg} / \mathrm{m}^{2}\right)$ \\
\hline SCG $(\mathrm{n}=17)$ & $48.65 \pm 8.33$ & $157.00 \pm 7.84$ & $62.11 \pm 10.47$ & $24.70 \pm 2.91$ \\
OPEG $(\mathrm{n}=20)$ & $41.30 \pm 5.81$ & $160.80 \pm 4.21$ & $64.12 \pm 10.28$ & $24.73 \pm 3.37$ \\
MPEG $(\mathrm{n}=16)$ & $43.44 \pm 7.67$ & $160.50 \pm 5.94$ & $57.18 \pm 7.32$ & $22.14 \pm 2.18$ \\
Sig. & 0.078 & 0.177 & 0.027 & 0.263 \\
\hline
\end{tabular}

Values are presented as mean \pm standard deviation.

BMI, body mass index; SCG, symptomatic control group; OPEG, Oov Pilates exercise group; MPEG, mat Pilates exercise group; Sig., statistical significance among three groups.
(MPEG) $(\mathrm{n}=16)$, and symptomatic control group (SCG) $(\mathrm{n}=17)$ (Table 1). During the 8-week intervention, no subject was withdrawn from three groups. Experimental criteria to include the subject in this study were as follow: (a) women experiencing the natural multiparity less than 3 times; (b) women occasionally experiencing the detectable symptoms in question 4 (urinary incontinence-related abscess) and question 6 (compressive incontinence) in the Bristol Female Lower Urinary Tract Symptoms Questionnaire; (c) women with at least one episode of urinary incontinence per a week or more than 10 episodes of urinary incontinence per a week. This study was conducted based on Institutional Review Board (IRB) of Korea University (approved IRB code: KUIRB2019-0087-01).

\section{Pilates program protocol and Oov}

OPEG used the Oov (HF Industries Pty Ltd, Taren Point, Australia) (Fig. 1) known as an ergonomic-shape form that can create the natural curve of the spine, which can help to stimulate the anatomical movement of spine and abdominal muscle contraction whereas MPEG used a general exercise mattress in normal Pilates program settings. Pilates program consisted of a 10-min warm-up, 40-min main exercise (phases I \& II), and 10-min cool-down, and was performed 3 times a week for 8 weeks the intervention of which was designed to improve the abdominal muscle and PFM (Table 2).

\section{Ultrasonopraphy - abdominal muscle thickness}

Thickness of rectus abdominis, external oblique abdominis, internal oblique abdominis, and transversus abdominis was measured

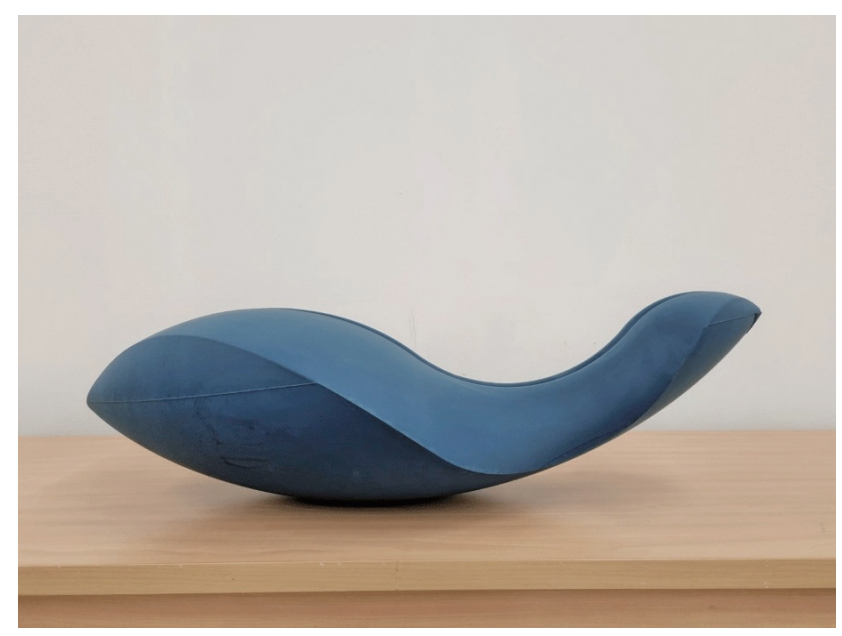

Fig. 1. Oov (HF Industries Pty Ltd, Taren Point, Australia) used as an exercise interventional tool in Oov Pilates exercise group. 
Table 2. 8-Week Oov and mat Pilates program

\begin{tabular}{|c|c|c|c|c|}
\hline Intervention method & & Exercise program & Frequency & Intensity \\
\hline \multirow[t]{2}{*}{ Oov Pilates (Oov) } & Warm-up & Breathing $\rightarrow$ Stretch $\rightarrow$ Imprint and release $\rightarrow$ Arm \& Knee circle & NA & NA \\
\hline & $\begin{array}{l}\text { Main exercise } \\
\text { phase I \& II } \\
\text { (40 min) }\end{array}$ & $\begin{array}{l}\text { Phase I (20 min) } \\
\text { Spin stretch forward } \rightarrow \text { Spin twist Saw } \rightarrow \text { Mermaid Roll-up } \rightarrow \text { Rolling like a ball } \rightarrow \\
\quad \text { Single leg stretch } \rightarrow \text { Single leg circles } \rightarrow \text { Shoulder bridge } \rightarrow \text { Swan } \rightarrow \text { Swimming }\end{array}$ & $\begin{array}{l}\text { 1-4 weeks } \\
10-20 \text { reps } \times 2-6 \text { sets } \\
\text { (Each set has } 30 \text {-sec rest) }\end{array}$ & $\begin{array}{c}55 \%-65 \% \text { HRR } \\
\text { (RPE 11-13) }\end{array}$ \\
\hline \multirow[t]{2}{*}{ Mat Pilates (Mat) } & & $\begin{array}{l}\text { Phase II (20 min) } \\
\text { The hundred } \rightarrow \text { Spin twist } \rightarrow \text { Saw } \rightarrow \text { Double leg stretch } \rightarrow \text { Double leg circles } \rightarrow \\
\text { Side leg circle } \rightarrow \text { Curl up Teaser } \rightarrow \text { Criss cross } \rightarrow \text { Inner thigh lifts } \rightarrow \text { Shoulder } \\
\text { bridge } \rightarrow \text { Swan dive } \rightarrow \text { Swimming }\end{array}$ & $\begin{array}{l}5-8 \text { weeks } \\
10-40 \text { reps } \times 2-6 \text { sets } \\
\text { (Each set has } 30 \text {-sec rest) }\end{array}$ & $\begin{array}{c}65 \%-75 \% \text { HRR } \\
\text { (RPE 13-15) }\end{array}$ \\
\hline & $\begin{array}{l}\text { Cool-down } \\
\text { (10 min) }\end{array}$ & Breathing $\rightarrow$ Stretch $\rightarrow$ Cat stretch $\rightarrow$ Child's pose & NA & NA \\
\hline
\end{tabular}

NA, no application; HRR, heart rate reserve.

Table 3. The change of abdominal muscle thickness

\begin{tabular}{|c|c|c|c|c|c|c|c|}
\hline Variable & Group & Pre (mm) & Post (mm) & $\Delta(\%)$ & $A^{p}$ & $A^{A}$ & $A^{B}$ \\
\hline \multirow[t]{3}{*}{ Rectus abdominis } & SCG & $0.86 \pm 0.11$ & $0.83 \pm 0.10$ & -3.49 & 0.250 & \multirow[t]{3}{*}{$0.003^{* *}$} & \multirow{3}{*}{$\begin{array}{l}\text { OPEG }>\text { SCG }(P=0.002)^{* *} \\
\text { MPEG }>\text { SCG }(P=0.208)\end{array}$} \\
\hline & OPEG & $0.79 \pm 0.18$ & $1.09 \pm 0.28$ & 37.97 & $0.001^{* *}$ & & \\
\hline & MPEG & $0.92 \pm 0.10$ & $1.01 \pm 0.27$ & 9.78 & 0.140 & & \\
\hline \multirow[t]{3}{*}{ External oblique abdominis } & SCG & $0.86 \pm 0.11$ & $0.83 \pm 0.10$ & -17.53 & $0.048^{*}$ & \multirow[t]{3}{*}{$0.011^{*}$} & \multirow{3}{*}{$\begin{array}{l}\text { OPEG }>\text { SCG }(P=0.022)^{*} \\
\text { MPEG }>\text { SCG }(P=0.013)^{*}\end{array}$} \\
\hline & OPEG & $0.79 \pm 0.18$ & $1.09 \pm 0.28$ & 12.24 & 0.140 & & \\
\hline & MPEG & $0.92 \pm 0.10$ & $1.01 \pm 0.27$ & 15.15 & 0.170 & & \\
\hline \multirow[t]{3}{*}{ Internal oblique abdominis } & SCG & $0.96 \pm 0.20$ & $0.88 \pm 0.22$ & -8.33 & 0.195 & \multirow[t]{3}{*}{$0.041^{*}$} & \multirow{3}{*}{$\begin{array}{l}\text { OPEG }>\text { SCG }(P=0.036)^{*} \\
\text { MPEG }>\text { SCG }(P=0.436)\end{array}$} \\
\hline & OPEG & $0.79 \pm 0.18$ & $1.09 \pm 0.28$ & 34.69 & $0.012^{*}$ & & \\
\hline & MPEG & $0.92 \pm 0.10$ & $1.01 \pm 0.27$ & 19.35 & 0.262 & & \\
\hline \multirow[t]{3}{*}{ Transversus abdominis } & SCG & $0.99 \pm 0.26$ & $0.99 \pm 0.19$ & 0 & 0.966 & \multirow[t]{3}{*}{$0.001^{* *}$} & \multirow{3}{*}{$\begin{array}{l}\text { OPEG }>\text { SCG }(P=0.001)^{*} \\
\text { MPEG }>\text { SCG }(P=0.131)\end{array}$} \\
\hline & OPEG & $1.02 \pm 0.35$ & $1.88 \pm 0.57$ & 84.31 & $0.001^{* *}$ & & \\
\hline & MPEG & $0.96 \pm 0.22$ & $1.38 \pm 0.65$ & 43.75 & $0.035^{*}$ & & \\
\hline
\end{tabular}

Values are presented as mean \pm standard deviation.

SCG, symptomatic control group; OPEG, Oov Pilates exercise group; MPEG, mat Pilates exercise group; $\Delta(\%)$, (Post-Pre)/Pre $\times 100 ; A^{p}$, paired $t$-test; $A^{A}$, analysis of covariance test; $A^{B}$, Bonferroni post hoc test.

${ }^{*} P<0.05 .{ }^{*} P<0.005$

using SONON Convex 300C (Sonon 300C, Healcerion Co., Seoul, Korea) with multiple frequencies technology and convex array transducer. The transducer was located at $5 \mathrm{~cm}$ below the $3 \mathrm{~cm}$ lateral of the xiphoid process for rectus abdominis and $2.5 \mathrm{~cm}$ inward of the axillary line between the iliac crest and the 12th rib inferior line for external oblique abdominis, internal oblique abdominis, and transversus abdominis. Using the Image-Pro Plus (Media Cyberbetics Inc., Silver Spring, MD, USA) for image analysis, anatomical thickness of each muscle was calculated (Table 3).

\section{Ultrasonopraphy - functional movement of PFM}

Functional movement of PFM was measured by same device used for abdominal muscle thickness. This study applied the previously approved clinical procedures for measuring the functional movement of PFM (Arab et al., 2009), which was operated by one designated practitioner. Small value in functional movement of PFM indicates the relatively improved ability of PFM, and vice versa (Table 4).

\section{Data analysis and processing}

All data were analyzed using IBM SPSS Statistics ver. 21.0 (IBM Co., Armonk, NY, USA). Analysis of covariance (ANCOVA) tests was performed to confirm the statistical differences between groups, and pre-post comparison within each group was conducted using the paired $t$-test. To confirm the statistical execution requisite of ANCOVA, 251 subjects was required when power analysis using G*Power (Erdfelder et al., 1996), which, however, our study could not meet the statistically-required experimental design due to time and financial constraints. Additionally, in ANCOVA, measured experimental values in preintervention were set as a covariate. Bon- 
Table 4. The change in functional movement of PFM and LUTS clinical score

\begin{tabular}{|c|c|c|c|c|c|c|c|}
\hline Variable & Group & Pre (mm) & Post (mm) & $\Delta(\%)$ & $A^{p}$ & $A^{A}$ & $A^{B}$ \\
\hline \multirow[t]{3}{*}{ FMP } & SCG & $0.92 \pm 0.09$ & $0.82 \pm 0.32$ & -10.87 & 0.242 & \multirow[t]{3}{*}{$0.001^{* *}$} & \multirow{3}{*}{$\begin{array}{l}\text { OPEG }>\text { SCG }(P=0.001)^{* *} \\
\text { MPEG }>\text { SCG }(P=1.000)\end{array}$} \\
\hline & OPEG & $0.84 \pm 0.13$ & $0.41 \pm 0.16$ & -51.19 & $0.001^{* *}$ & & \\
\hline & MPEG & $0.99 \pm 0.17$ & $0.74 \pm 0.39$ & -25.25 & $0.023^{*}$ & & \\
\hline \multicolumn{8}{|c|}{ LUTS clinical score } \\
\hline \multirow[t]{3}{*}{ DVS } & SCG & $48.09 \pm 12.12$ & $48.41 \pm 15.06$ & 0.67 & 0.884 & \multirow[t]{3}{*}{$0.001^{* *}$} & OPEG $<$ SCG $(P=0.001)^{* *}$ \\
\hline & OPEG & $51.35 \pm 9.08$ & $23.68 \pm 5.54$ & -53.89 & $0.001^{* *}$ & & MPEG $<$ SCG $(P=0.001)^{* *}$ \\
\hline & MPEG & $52.44 \pm 9.14$ & $22.88 \pm 4.39$ & -56.36 & $0.001^{* *}$ & & \\
\hline \multirow[t]{3}{*}{ DVD } & SCG & $22.29 \pm 4.36$ & $26.06 \pm 5.38$ & 16.91 & 0.955 & \multirow[t]{3}{*}{$0.001^{* *}$} & \multirow{3}{*}{$\begin{array}{l}\text { OPEG }<\text { SCG }(P=0.001)^{* *} \\
\mathrm{MPEG}<\mathrm{SCG}(P=0.001)^{* *}\end{array}$} \\
\hline & OPEG & $20.88 \pm 3.17$ & $12.68 \pm 3.57$ & -39.27 & $0.001^{* *}$ & & \\
\hline & MPEG & $25.94 \pm 4.78$ & $12.00 \pm 3.25$ & -53.73 & $0.001^{* *}$ & & \\
\hline
\end{tabular}

Values are presented as mean \pm standard deviation.

FMP, functional movement of PFM; LUTS, lower urinary track symptoms; DVS, degree of voiding-related symptom; DVD, degree of voiding-related discomfort; SCG, symptomatic control group; OPEG, Oov Pilates exercise group; MPEG, mat Pilates exercise group; $\Delta(\%)$, (Post-Pre)/Pre $\times 100 ; A^{p}$ : paired $t$-test; $A^{A}$, ANCOVA test; $A^{B}$, Bonferroni post hoc test.

${ }^{*} P<0.05 .{ }^{* *} P<0.005$

ferroni as a post hoc test was used to perform the multiple comparison among groups. All analyzed values were expressed as mean \pm standard deviation. Statistical significance level was set at $P<0.05$.

\section{RESULTS}

\section{Thickness of rectus abdominis}

After 8-week Pilates intervention, the thickness of rectus abdominis showed a significant difference among groups $(P=0.003)$; in the Bonferroni post boc test, OPEG showed the significantly increased rectus abdominis thickness compared to SCG $(P=0.002)$ whereas MPEG was not statistically differentiated from SCG $(P=$ 0.208) (Table 3).

\section{Thickness of external oblique abdominis}

After 8-week Pilates program, the thickness of external oblique abdominis showed a significant thickness difference among groups $(P=0.011)$; in the Bonferroni post hoc test, OPEG $(P=0.022)$ and MPEG $(P=0.013)$ showed the significantly increased external oblique abdominis thickness compared to that of SCG.

\section{Thickness of internal oblique abdominis}

After 8-week Pilates intervention, the thickness of internal oblique abdominis showed a significant thickness difference in internal oblique abdominis among groups $(P=0.041)$; in the Bonferroni post hoc test, only OPEG had a significant internal oblique abdominis thickness compared to SCG $(P=0.036)$, not in MPEG $(P=0.436)$.

\section{Thickness of transversus abdominis}

After 8-week Pilates program, the thickness of transversus abdominis showed a significant thickness difference in among groups $(P=0.001)$; in the Bonferroni post boc test, only OPEG showed a significant increase of transversus abdominis thickness compared to SCG $(P=0.001)$, but not in MPEG $(P=0.131)$ (Table 3).

\section{Functional movement of PFM}

After the 8-week Pilates intervention, functional movement of PFM showed a significant difference in among groups $(P=0.001)$; OPEG showed a significant improvement of FMP compared to SCG $(P=0.001)$, but not in MPEG in Bonferroni post hoc test $(P=$ 1.000) (Table 4).

\section{LUTS clinical score in BFLUTS - degree of voiding-related symptoms and discomfort}

After the 8-week Pilates intervention, significant difference in degree of voiding-related symptoms was found among groups $(P=0.001)$; SCG showed a significantly higher degree of voidingrelated symptoms compared to both OPEG $(P=0.001)$ and MPEG $(P=0.001)$ in Bonferroni post boc test (Table 4). Degree of voidingrelated discomfort showed a significant difference among groups $(P=0.001)$; significantly increased degree of voiding-related discomfort was shown in SCG compared to both OPEG $(P=0.001)$ and MPEG $(P=0.001)$ in Bonferroni post hoc test (Table 4).

\section{DISCUSSION}

The aim of our study was to investigate the efficacy of Pilates 
program using Oov and mat on abdominal muscles thickness, functional movement of PFM, and LUTS clinical score in middleaged Korean women between 40-55 years diagnosed with LUTS. Our study found that Pilates program using the Oov was the key intervention that significantly increased the all part of abdominal muscles thickness, except the external oblique abdominis. Among all part of abdominal muscles thickness in OPEG and MPEG, the fact that transversus abdominis in OPEG had the most prominent improvement (OPEG: 84.31\% $\uparrow, P<0.005$; MPEG: $43.75 \% \uparrow$, $P<0.05)$ indicated that the application of Oov can have a greater impact on developing the abdominal muscles thickness compared to the mat. As transversus abdominis is the most important abdominal muscle for abdominal pressure regulation and core stabilization (Hodges and Richardson, 1999) and associated with managing the urinary symptoms (Bø and Herbert, 2013), the significant change of transversus abdominis derived by the use of Oov can provide an interventional benefit in managing LUTS.

PFM has been assumed to interrelate with the function of the lower urinary tract and facilitate the synergistic action between the diaphragm and abdominal muscles to maintain intraperitoneal pressure (Talasz et al., 2010), which is also proved in our study that functionally improved PFM alleviated the voiding-associated symptom and discomfort score (Table 4). In degree of voiding-related symptom and discomfort, considering that Pilates interventional group using Oov and mat showed the mitigated clinical tendency, it is speculated that both Oov and mat were a powerful exercise interventional tool to manage the voiding-related symptom and discomfort. However, since the OPEG showed a globally developed abdominal muscles thickness compared to MPEG (Table 3), the application of Oov can be an optimal interventional choice to enhance the abdominal muscles and functional movement of PFM in term of managing the LUTS, which was also demonstrated in another study that Pilates using Oov has a kinesiological potentiality to improve the thickness of the abdominal muscles (Gibbons and Bird, 2019). It is thought that the vigorous abdominal movement can be produced during the use of Oov the uneven shape of which could provide OPEG with the favorable condition that developed the abdominal muscles thickness more efficiently than that of MPEG. As previous study also reported that abdominal endurance and strength can be achieved by use of uneven-shaped exercise apparatus such as the gym ball and foam roller (Kloubec, 2010), Pilates using Oov is reflective of optimized exercise intervention to improve the functional movement of PFM as well as abdominal muscles thickness, which concurs in scientific notion with previous investigations (Gibbons and Bird, 2019;
Kang et al., 2021).

In our result, as the OPEG showed the most dramatic change in rectus abdominis, internal oblique abdominis, and transversus abdominis, it is speculated that morphological change in abdominal muscles was be directly associated with ameliorated functional movement of PFM (Tables 3 and 4), which was consistent with previous studies (Kang et al., 2021; Thompson et al., 2006). Most importantly, since the improved PFM function in urinary incontinence symptoms was recognized to mitigate the urinary incontinence symptoms (Sapsford, 2004), and functional movement of PFM can be maximized with activated abdominal muscle during Pilates program (Thompson et al., 2006), we can suggest that the Oov is a clinically affordable intervention in the setting of Pilates program.

LUTS can be defined as urological symptoms associated with the storage and excretion of urine; aging, attenuated bladder contractility, decreased bladder volume, abdominal obesity, and weakened PFM were reported as a major cause of LUTS (Milsom, 2009), which can deteriorate the quality of life in general people suffering from LUTS. Given that overall LUTS clinical score and functional movement of PFM was regained by more than $50 \%$ after 8 -week Oov Pilates (Table 4), interventional benefit of Oov can affect more than just improving the anatomical change in abdominal muscles thickness and PFM. Eventually, improved abdominal muscles thickness and functional movement of PFM can teleologically provide the superior quality of life the phenomenon of which was demonstrated by alleviated LUTS clinical score (Table 4). One study also provided a scientific consensus that Pilates per se can be an effective exercise intervention to improve the lifestyle quality associated with urinary incontinence symptoms (Chmielewska et al., 2019). Hence, mitigated degree of voiding-related symptom and discomfort in our study could be attained when the use of Oov is met during Pilates program. In this sense, although statistical significance was found in both OPEG and MPEG (Table 4), overall improvement of OPEG in abdominal muscles thickness may be a supplementary advantage to further ameliorate the lifestyle quality related to urological symptoms this is because the overall positive change of abdominal muscles thickness in OPEG can function as a synergistic element that helps to enhance the functional movement of PFM.

Consequently, our results highlighted that Pilates using Oov and mat can ameliorate the abdominal muscles thickness and functional movement of PFM potentially associated with alleviated LUTS, however, the application of Oov in Pilates program settings can be more effective countermeasure in managing the LUTS. 
Therefore, we speculate that 8-week Pilates using Oov can be more suitable exercise intervention to accomplish the improved abdominal muscles thickness and functional movement of PFM and contented quality of life in middle-aged women with LUTS.

\section{CONFLICT OF INTEREST}

No potential conflict of interest relevant to this article was reported.

\section{ACKNOWLEDGMENTS}

The authors received no financial support for this article.

\section{REFERENCES}

Abrams P, Cardozo L, Fall M, Griffiths D, Rosier P, Ulmsten U, Van Kerrebroeck $\mathrm{P}$, Victor A, Wein A. The standardisation of terminology in lower urinary tract function: report from the standardisation sub-committee of the International Continence Society. Urology 2003;61:37-49.

Arab AM, Behbahani RB, Lorestani L, Azari A. Correlation of digital palpation and transabdominal ultrasound for assessment of pelvic floor muscle contraction. J Man Manip Ther 2009;17:e75-e79.

$\mathrm{B} ø \mathrm{~K}$, Herbert RD. There is not yet strong evidence that exercise regimens other than pelvic floor muscle training can reduce stress urinary incontinence in women: a systematic review. J Physiother 2013;59:159168.

Chmielewska D, Stania M, Kucab-Klich K, Błaszczak E, Kwaśna K, Smykla A, Hudziak D, Dolibog P. Electromyographic characteristics of pelvic floor muscles in women with stress urinary incontinence following sEMG-assisted biofeedback training and Pilates exercises. PLoS One 2019;14:e0225647.

Coyne KS, Sexton CC, Irwin DE, Kopp ZS, Kelleher CJ, Milsom I. The impact of overactive bladder, incontinence and other lower urinary tract symptoms on quality of life, work productivity, sexuality and emotional well-being in men and women: results from the EPIC study. BJU Int 2008;101:1388-1395.

Davila GW, Guerette N. Current treatment options for female urinary incontinence-a review. Int J Fertil Womens Med 2004;49:102-112.

Erdfelder E, Faul F, Buchner A. GPOWER: a general power analysis pro- gram. Behav Res Methods Instrum Comput 1996;28:1-11.

Fayh A, Brodt GA, Souza C, Loss JF. Pilates instruction affects stability and muscle recruitment during the long stretch exercise. J Bodyw Mov Ther 2018;22:471-475.

Gibbons TJ, Bird ML. Exercising on different unstable surfaces increases core abdominal muscle thickness: an observational study using real-time ultrasound. J Sport Rehabil 2019;28:803-808.

Hodges PW, Gandevia SC. Changes in intra-abdominal pressure during postural and respiratory activation of the human diaphragm. J Appl Physiol 2000;89:967-976.

Hodges PW, Richardson CA. Transversus abdominis and the superficial abdominal muscles are controlled independently in a postural task. Neurosci Lett 1999;265:91-94.

Kang G, Lee H, Shin M, Kim J, Lee S, Park Y. The efficacy of Pilates on urinary incontinence in Korean women: a metabolomics approach. Metabolites 2021;11:118.

Kim ST, Lee JH. The effects of Pilates breathing trainings on trunk muscle activation in healthy female subjects: a prospective study. J Phys Ther Sci 2017;29:194-197.

Kim TB, Kim CH, Kim KT, Yoon SJ, Chung KJ. Urology as rehabilitation medicine: a literature review. J Exerc Rehabil 2018;14:322-326.

Kloubec JA. Pilates for improvement of muscle endurance, flexibility, balance, and posture. J Strength Cond Res 2010;24:661-667.

Milsom I. Lower urinary tract symptoms in women. Curr Opin Urol 2009; 19:337-341.

Sapsford R. Rehabilitation of pelvic floor muscles utilizing trunk stabilization. Man Ther 2004;9:3-12.

Sapsford RR, Richardson CA, Maher CF, Hodges PW. Pelvic floor muscle activity in different sitting postures in continent and incontinent women. Arch Phys Med Rehabil 2008;89:1741-1747.

Talasz H, Kofler M, Kalchschmid E, Pretterklieber M, Lechleitner M. Breathing with the pelvic floor? Correlation of pelvic floor muscle function and expiratory flows in healthy young nulliparous women. Int Urogynecol J 2010;21:475-481.

Thompson JA, O'Sullivan PB, Briffa NK, Neumann P. Differences in muscle activation patterns during pelvic floor muscle contraction and Valsalva maneuver. Neurourol Urodyn 2006;25:148-155.

Yoo TK, Lee KS, Sumarsono B, Kim ST, Kim HJ, Lee HC, Kim SH. The prevalence of lower urinary tract symptoms in population aged 40 years or over, in South Korea. Investig Clin Urol 2018;59:166-176. 